\title{
Epilepsy in a Young Adult Caused by L-2-Hydroxyglutaric Aciduria: A Case Report
}

\author{
Vembu Periasamy ${ }^{\mathrm{a}}$ Mohd Rudwan $^{\mathrm{b}}$ Girish Yadav ${ }^{c}$ Riyadh A. Khan ${ }^{\mathrm{a}}$ \\ Departments of ${ }^{a}$ Neurology, ${ }^{b}$ Neuroradiology and ${ }^{C}$ Laboratory Medicine, Ibn Sina Hospital, Kuwait
}

\section{Key Words}

L-2-Hydroxyglutaric aciduria $\cdot$ Organic acids •

Gas chromatography-mass spectrometry •

Cerebrospinal fluid $\cdot$ Magnetic resonance imaging .

Electroencephalography $\cdot$ White matter

\begin{abstract}
Objective: To report the importance of a rare organic acid metabolic disorder, L-2-hydroxyglutaric aciduria, and its characteristic neuroimaging cerebral white matter abnormalities in a case of epilepsy. Subject and Methods: A 19year-old male presented with an 11-year history consisting of school failures, intellectual deterioration and generalized tonic-clonic convulsions. Results: Neurological examination showed mental subnormality, mild dysarthria and bilateral pyramidal signs. Computed tomography and magnetic resonance imaging (MRI) of the brain showed characteristic white matter lesions, suggestive of L-2-hydroxyglutaric aciduria. The diagnosis of this disease was confirmed by elevated urinary concentrations of L-2-hydroxyglutaric acid. The epilepsy was partially controlled with antiepileptic drugs. Conclusion: This report indicates the importance of routine examination of urinary organic acids in children and young adults presenting with chronic encephalopathy and epilepsy with characteristic MRI white matter lesions. L-2-hydroxyglutaric aciduria should be considered as one of the differential diagnoses of epilepsy.

Copyright $\odot 2008$ S. Karger AG, Basel
\end{abstract}

\section{Introduction}

$\mathrm{L}$-2-hydroxyglutaric aciduria (L-2-OHGA) is a recently described rare metabolic disorder of organic acidurias, first described in 1980 in a 5-year-old boy with psychomotor retardation and leukodystrophy [1]. This rare disorder of organic acid metabolism has been recognized with increased frequency around the world [2,3]. Magnetic resonance imaging (MRI) of the brain shows a characteristic radiological pattern and distribution with severe progressive loss of myelinated arcuate fibers and peripheral white matter abnormalities in the cerebral hemispheres, cerebellar atrophy and abnormal signal intensity in the basal ganglia and dentate nuclei $[4,5]$. We report a case of L-2OHGA in a young adult with normal childhood development, who presented with mental deterioration, epilepsy and characteristic MRI white matter lesions.

\section{Case Report}

A 19-year-old male presented with an 11-year history of mental subnormality, repeated school failure, slowly declined mental function and recurrent generalized tonic-clonic convulsions. He was born to nonconsanguineous healthy parents with normal delivery and had had a normal childhood development up to the age of 8 . He had studied up to the 4 th class and discontinued education. Ten years before admittance, he had developed recurrent generalized tonic-clonic convulsions, lasting 3-5 min, associated

\section{KARGER}

Fax +4161306 1234

E-Mail karger@karger.ch

www.karger.com
(C) 2008 S. Karger AG, Basel

1011-7571/08/0173-0258\$24.50/0

Accessible online at:

www.karger.com/mpp
Dr. V. Periasamy

Department of Neurology

Ibn Sina Hospital, PO Box 25427

Safat 13115 (Kuwait)

Tel. +965 4840 837, Fax +965 4849 226, E-Mail drperiasamy06@yahoo.com 


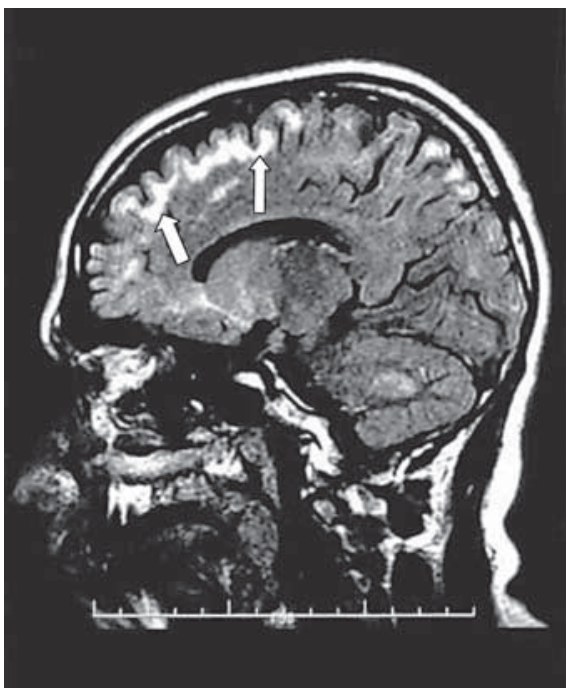

Fig. 1. Sagittal FLAIR MR image showing the characteristic subcortical high signal intensities involving the U fibers (arrows), sparing the periventricular white matter.

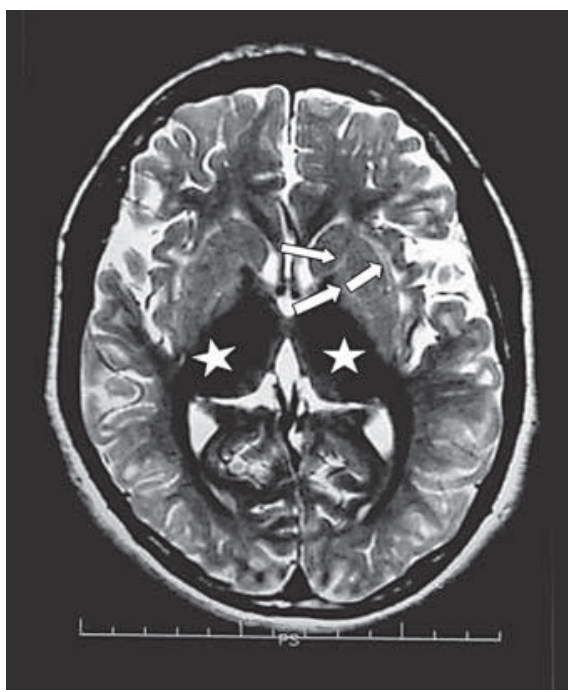

Fig. 2. Axial $T_{2}$-weighted $M R$ image showing increased signal intensity in the internal and external capsules (thick arrows) and globus pallidi (thin arrow) as well as decreased signal intensity of the thalami (stars) with wide sylvian fissures.

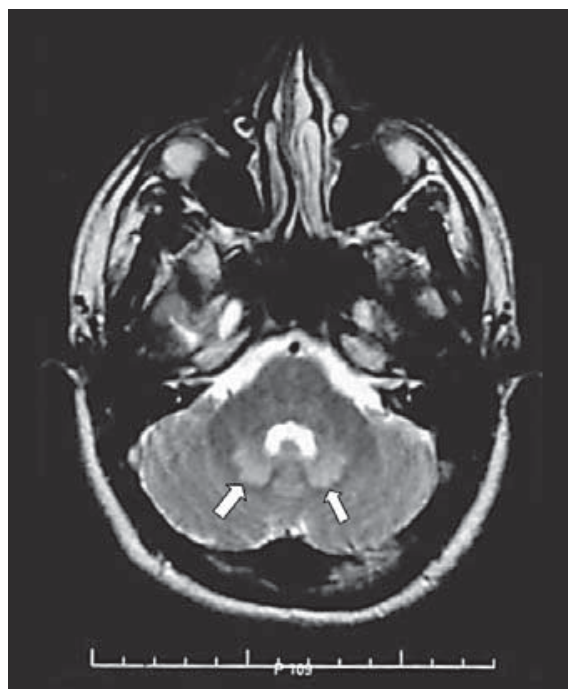

Fig. 3. Axial $\mathrm{T}_{2}$-weighted MR image showing increased signal intensity in both dentate nuclei (arrows) with no cerebellar atrophy. with tongue biting and incontinence of urine, followed by postictal confusion. The frequency of the seizures initially was once in 3-6 months and slowly increased to monthly, weekly and later almost daily 3-4 attacks. He presented with attention and memory deficits along with poor concentration and mild dysarthric speech.

The rest of the neurological examination showed mental subnormality and a Mini Mental score of 20/30 with an IQ of approximately 60 . Optic fundus examination was normal. His head circumference was $55 \mathrm{~cm}$. Muscle strength, assessed according to the Medical Research Committee scale, was 4/5 in the upper and lower limb muscles. He had generalized hyperreflexia with equivocal plantar response. No cerebellar signs or gait disturbance were noticed. CT scan of the brain showed multiple hypodense areas in the frontal white matter bilaterally. MRI study $\left(\mathrm{T}_{2^{-}}\right.$ weighted and FLAIR images) showed high signal lesions in the subcortical white matter without affecting the corpus callosum or periventricular areas, mainly involving the arcuate fibers peripherally (fig. 1). An axial $\mathrm{T}_{2}$-weighted $\mathrm{MR}$ image showed increased signal intensity in the internal and external capsules, globus pallidi and decreased signal intensity of both thalami, with wide sylvian fissures (fig. 2), but increased signal intensity in the dentate nuclei and no cerebellar atrophy was seen (fig. 3). MR spectroscopy study $(\mathrm{TR}=1,500 ; \mathrm{TE}=144$ and $\mathrm{TE}=35)$ showed a mild decrease of $\mathrm{N}$-acetyl aspartate and choline peaks; no myoinositol peak was found at TE $=35$ (fig. 4).

Cerebrospinal fluid was acellular with normal glucose content, and CSF protein was $466 \mathrm{mg} / \mathrm{l}$ (ref. range: 150-450); no oligoclonal bands were present. Serum and CSF virology screening tests were negative. Thyroid function tests as well as arylsulfatase activity in leukocytes and very long chain fatty acid levels in plas- ma were normal. Urinary organic acid analysis by gas chromatography-mass spectrometry revealed elevated concentrations of L-2-hydroxyglutaric (L-2-OHG) acid. Plasma lysine concentration was $390 \mu \mathrm{mol} / \mathrm{l}$ (reference range: 75-215). These findings were consistent with the diagnosis of L-2-OHGA. EEG recordings showed abnormal focal paroxysmal activities on a slow and irregular background. Nerve conduction studies were normal. The patient was treated with anticonvulsants, including phenytoin and oxycarbamazepine. Under this regimen, his epileptic seizures were controlled.

\section{Discussion}

L-2-OHGA is a recently described rare metabolic disorder, characterized by increased levels of L-2-OHG acid in urine, plasma and cerebrospinal fluid. In healthy subjects, $\mathrm{L}-2-\mathrm{OHG}$ acid is equally present in urine in $\mathrm{D}$ and $\mathrm{L}$ configurations. L-2-OHG acid is detected in trace amounts in the urine of healthy subjects by gas chromatography-mass spectrometry analysis, but in this patient it was elevated. Apparently an elevated level of L-2-OHG acid causes L-2-OHGA, which is an inherited autosomal recessive trait, expressed as a slowly progressive encephalopathy, causing mental regression, seizures and severe cerebellar dysfunction, as well as pyramidal and extrapyramidal signs $[2,3,6]$ as observed in this patient. 


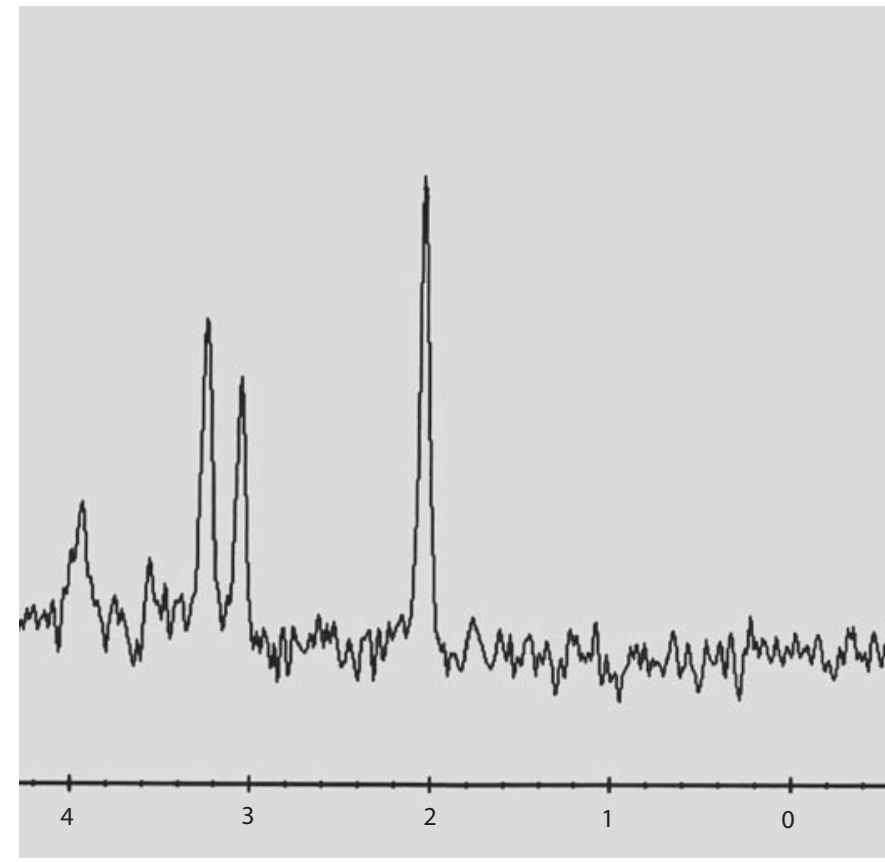

Fig. 4. $M R$ spectroscopy, using $T R=1,500$ and $T E=144$, shows mild decrease of $\mathrm{N}$-acetyl aspartate and choline peaks.

Febrile convulsions, partial and grandmal seizures have often been reported and are generally difficult to control [5], similar to our patient, who required polytherapy. The recurrent generalized tonic-clonic convulsions may be due to severe subcortical involvement. Macrocephaly is a common finding in L-2-OHGA. However, this finding was not present in our patient. Macrocephaly occurs when the disease manifests itself before the closure of the cranial sutures, possibly as a result of edematous swelling of the cerebral hemispheres. Later, resolution of the swelling followed by atrophy of the white matter probably accounts for the absence of macrocephaly in older subjects, as seen in our patient. The typical MRI signal abnormalities are detectable in the cerebral white matter, cerebellum and basal ganglia $[4,5]$.

Their combined appearance is highly suggestive of L-2-OHGA. The most striking MRI features consist of scattered or diffuse subcortical white matter lesions which fade centripetally. The subcortical lesions are clearly visible in $\mathrm{T}_{1}$-weighted, $\mathrm{T}_{2}$-weighted and FLAIR images and consist of diffuse high signal changes in the cerebral white matter of the frontal and parietal lobes, although the periventricular white matter and corpus callosum are usually spared $[4,5,7]$.
Cerebellar disturbances have been reported in many case reports and could be related both to cerebellar atrophy and to the selective involvement of the dentate nuclei. Interestingly, no cerebellar signs including either ataxia or cerebellar atrophy in the neuroimaging studies were present in our patient. The involvement of the basal ganglia, particularly the globus pallidus, is constant but less severe. Barth et al. [3] reported the involvement of the caudate nuclei and putamen, with sparing of the globus pallidus, in L-2-OHGA. In our patient, only the globus pallidus was involved. Though considered not specific, decreased signal intensity in the thalami on $\mathrm{T}_{2}$-weighted images (fig. 2), as in our case, have been observed in many patients described earlier $[4,5,7]$. The neurological picture and the slowly progressive clinical course could have been responsible for misdiagnosis and underestimation of the L-2-OHGA, particularly in the early stages of the disease in our patient. Nevertheless, the typical MRI pattern of a subcortical leukoencephalopathy was present at the onset of the symptoms; its correct recognition appears to be crucial in addressing the metabolic investigations, including the urinary organic acid analysis.

Hanefeld et al. [8] reported that proton MR spectroscopy study in a patient with L-2-OHGA revealed a decrease in the neuronal marker $\mathrm{N}$-acetyl aspartate and in choline and an increase in the myoinositol peaks. Similar findings were seen in our patient, but no increase of myoinositol peak occurred [9].

By means of homozygosity mapping studies, the disease-causing mutant gene i.e. duranin $\left(\mathrm{C}_{14}\right.$-orf 160$)$ located on chromosome 14q22.1 was recently identified by Topcu et al. [10]. The duranin gene encodes a putative mitochondrial protein with homology to FAD-dependent oxidoreductases. This gene is expressed highly in the brain. The exact catalytic activity of this enzyme and its role in the intermediary metabolism are not known clearly. There could be a failure to catabolize L-2-OHGA due to the defective enzyme or accumulation of an unknown intermediate, leading to excess conversion of this substance to L-2-OHGA. Future studies will be needed to reveal the exact catalytic function of duranin [10]. At present no specific treatment is available for L-2-OHGA.

\section{Conclusion}

This case illustrates the use of brain MRI in the diagnosis of typical and almost characteristic findings due to L-2-OHGA, but the determination level of L-2-OHG acid is needed for confirmation of the diagnosis of the disease. 


\section{References}

-1 Duran M, Kimberling JP, Bakker HD, Van Gennip AH, Wadman SK: L-2-hydroxyglutaric aciduria: an inborn error of metabolism? J Inherit Metab Dis 1980;3:109-112.

$\checkmark 2$ Moroni I, D’Incerti L, Farina L, Rimoldi M, Uziel G: Clinical, biochemical and neuroradiological findings in L-2-hydroxyglutaric aciduria. Neurol Sci 2000;21:103-108.

$>3$ Barth PG, Hoffmann GF, Jaeken J, Wanders RJA, Duran M, Jansen GA, Jakobs C, Lehnert W, Hanefeld F, Valk J, Schutgens RBH, Trefz FK, Hartung HP, Chamoles NA, Sfaello Z, Caruso U: L-2-hydroxyglutaric academia: clinical and biochemical findings in 12 patients and preliminary report on L-2hydroxyglutaric acid dehydrogenase. J Inherit Metab Dis 1993;16:753-761.
-4 D’Incerti L, Farina L, Moroni I, Uziel G, Savoiardo M: L-2-hydroxyglutaric aciduria: MRI in seven cases. Neuroradiology 1998; 40:727-733.

$\checkmark 5$ Topcu M, Erdem G, Saatci I, Aktan G, Simsek A, Renda Y, Schutgens RBH, Wanders RJA, Jacobs C: Clinical and magnetic resonance imaging features of L-2-hydroxyglutaric acidemia: report of three cases in comparison with Canavan disease. J Child Neurol 1996;11:373-377.

6 Hoffman GF, Jakobs C, Holmes B, Mitchell L, Becker G, Hartung HP, Nyhan WL: Organic acids in cerebrospinal fluid and plasma of patients with L-2-hydroxyglutaric aciduria. J Inherit Metab Dis 1995;18:189-193.
7 Sztriha L, Gururaj A, Vreken P, Nork M, Lestringant GG: L-2-hydroxyglutaric aciduria in two siblings. Paediatr Neurol 2002; 27:141-144.

8 Hanefeld F, Kruse B, Bruhn H, Frahm J: In vivo proton magnetic resonance spectros copy of the brain in a patient with L-2-hydroxyglutaric aciduria. Pediatr Res 1994;35: 614-616.

9 Patay Z, Tortori-Donati P, Rossi A: Pediatric Neuroradiology. Berlin, Springer, 2005.

10 Topcu M, Jobard F, Halliez S, Coskun T, Yalcinkayal C, Gerceker FO, Wanders RJA, Prud'homme JF, Lathrop M, Ozguc M, Fischer J: L-2-hydroxyglutaric aciduria: identification of mutant gene C14orf160, localized on chromosome 14q22.1. Hum Mol Genet 2004;13:2803-2811. 